\title{
SOME ASPECTS OF THE CLINICAL PHARMACOLOGY OF NITROUS OXIDE
}

\author{
K. M. Leighton, M.B., CH.B., F.R.C.P. (C) * AND BEVERLY KOTH $†$
}

Nrtrous oxide has been employed in anaesthesia since the beginning of the art itself. $^{1}$ This anaesthetic agent, therefore, must be considered to have stood the test of time and there can surely be few anaesthetists who would find themselves questioning its safety. As it is employed in modern anaesthetic practice, nitrous oxide is generally regarded as an adjuvant to balanced anaesthesia with few disadvantages other than low potency.

It is well known, of course, that prolonged administration of this gas, for 24 hours or more, may be followed by leucopaenia ${ }^{2}$ and that this effect is a function of the ability of nitrous oxide to influence cell division. This property of the agent may, perhaps, have greater significance for operating room personnel undergoing daily exposure than for patients who are anaesthetised for surgical procedures. ${ }^{3}$

Nitrous oxide is capable of supporting combustion although it is not inflammable. ${ }^{4}$ This property of the agent is probably of limited clinical significance.

We are aware that the solubility of nitrous oxide in relation to that of nitrogen is as 30:1. ${ }^{5}$ Thus, air containing body cavities such as closed loops of bowel ${ }^{6}$ and cerebral ventricles during air encephalography ${ }^{7}$ may undergo distention when nitrous oxide is employed in the inspired anaesthetic mixture, because the ready diffusion of the gas into these nitrogen-containing spaces is faster than the egress of the nitrogen.

At this point it is worth remarking how very frequently nitrous oxide is employed in modern anaesthetic practice. Since the pendulum has swung from the use of explosive agents (eschewing in particular cyclopropane and diethyl ether) nitrous oxide has been employed as an adjuvant for the volatile hydrocarbons, intravenous narcotics, the so-called dissociative anaesthetics and, accompanied by neuromuscular blockade and modest hyperventilation, as a principal anaesthetic agent in one form of balanced anaesthesia.

Indeed, it is reasonable to consider this agent as the leitmotiv against which the remainder of the symphony of much of modern general anaesthesia is currently played.

It is interesting, therefore, to note that until recently comparatively few studies of the pharmacology of this agent had been conducted. ${ }^{8,5}$ Its very marked record of apparent safety would appear to have protected it from searching clinical investigation or laboratory study until recent years.

*Assistant Professor, Department of Anaesthesia, Honorary Assistant Professor, Department of Pharmacology, University of British Columbia.

†Research Assistant, Department of Pharmacology, University of British Columbia.

This work was supported by a grant in aid of research awarded by the British Columbia Heart Foundation. 
It seems pertinent, therefore, to review some of the work which has been done with this interesting and valuable agent in the last few years.

\section{Potency of nitrous oxide}

The following argument is taken from Smith ${ }^{5}$ who has demonstrated in an elegant fashion that we can largely prove our clinical impressions regarding the potency of nitrous oxide.

It is convenient to consider the potency of an inhalational general anaesthetic in terms of Minimal Alveolar Concentration (M.A.C.). This concept has been particularly useful for the comparison of one anaesthetic agent with another. It is well known that the potency of many inhalational general anaesthetic agents is related to M.A.C. ${ }^{10}$ It can be shown that the product of M.A.C. and the oil/gas partition coefficient for many inhalational general anaesthetic agents is a constant. ${ }^{11}$ The figure for methoxyflurane, halothane, ether, cyclopropane and xenon is 143.

Since the oil/gas partition coefficient for nitrous oxide is 1.4 , then if the constant mentioned above applies in the case of nitrous oxide, M.A.C. for this agent should be 102 (i.e. $143 \div 1.4$ ).

It is possible to show that this is a reasonably correct figure and, at the same time, to demonstrate that when nitrous oxide is combined with another inhalation anaesthetic their combined effects are additive. How additive this effect is was shown clinically in 1964 by Saidman et al. ${ }^{12}$ who demonstrated that M.A.C. for halothane was reduced from 0.75 per cent to 0.29 per cent by the concomitant administration of nitrous oxide sufficient to produce an alveolar concentration of 65 per cent.

If these combinations be additive then it should be possible to compare fractions of M.A.C. for the two agents so that

$$
\mathrm{C}_{\mathrm{A}} \cdot \mathrm{a}+\mathrm{C}_{\mathrm{B}} \cdot \mathrm{b}=\mathrm{MAC}_{\mathrm{A}} \cdot \mathrm{a}=\mathrm{MAC}_{\mathrm{B}} \cdot \mathrm{b}
$$

where $\mathrm{C}_{\mathrm{A}}=$ concentration of anaesthetic $\mathrm{A}$

$$
\mathrm{A}=\text { oil/gas partition coefficient of anaesthetic } \mathrm{A}
$$

And similarly for $\mathrm{C}_{\mathrm{B}}$ and $\mathrm{b}$ for anaesthetic $\mathrm{B}$.

Substituting in the above equation:-

$$
\mathrm{MAC}_{\mathrm{b}}=\frac{\mathrm{C}_{\mathrm{B}} \cdot \mathrm{MAC}_{\mathrm{A}}}{\left(\mathrm{MAC}_{\mathrm{A}}-\mathrm{C}_{\mathrm{A}}\right)}
$$

Substituting Halothane $(\mathrm{H})$ for A

and Nitrous Oxide ( $N$ ) for $B$

$$
\mathrm{MAC}_{\mathrm{N}}=\frac{\mathrm{C}_{\mathrm{N}} \cdot \mathrm{MAC}_{\mathrm{H}}}{\left(\overline{\mathrm{MAC}} \overline{\mathrm{H}}_{\mathrm{H}}-\mathrm{C}_{\mathrm{H}}\right)}
$$

Then, since with 65 per cent $\mathrm{N}_{2} \mathrm{O}, \mathrm{MAC}_{\mathrm{H}}$ falls from 0.74 to 0.29 per cent

$$
\mathrm{MAC}_{\mathrm{N}}=\frac{65 \times 0.74}{0.74-0.29}=\frac{48.1}{0.45}=107
$$

(After Smith by kind permission of the author, editor and publisher ${ }^{5}$ ) 
Thus, from this equation, one derives the figure of 107 for MAC nitrous oxide. When fluroxene is substituted for halothane the figure obtained is 94 . The mean of these two (i.e. 107 and 94 ) is 101.

Hence, one may say that MAC for nitrous oxide is indeed about 101 per cent (compared with 0.74 per cent for halothane) and that the effects of this agent when used in conjunction with other general anaesthetic agents is indeed additive. This figure of 101 per cent (i.e. a partial pressure of 101 per cent of atmospheric pressure at sea level) can be confirmed by employing a hyperbaric technique for nitrous oxide administration.

Thus the validity of the concept of MAC and solubility coefficient product is confirmed in the case of nitrous oxide and a definitive appraisal of the potency of the agent is possible.

The maximal effect of nitrous oxide in clinical practice is, of course, limited by the necessity to maintain an adequate partial pressure of oxygen in the inspired gas. At least 30 per cent oxygen under normobaric conditions is necessary for this, in consequence of ventilation perfusion changes associated with the state of general anaesthesia especially. ${ }^{13,14}$ Thus 65 per cent to 70 per cent nitrous oxide are the concentrations commonly employed in clinical practice during controlled ventilation.

\section{Concentration effect}

It is perhaps worthwhile to consider the concentration effect, the concentrating effect, and the second gas effect of this agent. These have been described by a variety of authors and they have been recently considered anew by Drs. Stoelting and Eger. ${ }^{15}$

These phenomena stem from the fact that nitrous oxide is rapidly absorbed from pulmonary alveoli. In the initial period following the introduction of the gas to an inspired mixture there is a net uptake of nitrous oxide of one litre per minute when the inspired nitrous oxide concentration is 80 -per cent. ${ }^{5}$ In practice, as has been mentioned, this concentration is seldom employed.

Whether one is breathing air or oxygen prior to the introduction of 80 per cent nitrous oxide this figure obtains. In the case of air, only 3 per cent of nitrous oxide uptake per minute is replaced in the pulmonary alveolus by nitrogen. This is a function of the relative solubilities of nitrous oxide and nitrogen in body fluids and tissues, which have already been considered.

Since there is a net increase in uptake over excretion amounting to nearly 1 litre per minute, when 80 per cent $\mathrm{N}_{2} \mathrm{O}$ is inspired, it is clear that alveolar ventilation must increase by this amount if carbon dioxide tensions in alveolar gas and arterial blood are to remain constant.

If a mixture containing 80 per cent of nitrous oxide is administered to a patient who has been breathing air, then $1000 \mathrm{mls}$ per minute of nitrous oxide are absorbed from the alveoli and $30 \mathrm{mls}$ of nitrogen are returned to the alveoli from blood in exchange for this uptake. Thus 97 per cent of the volume of nitrous oxide absorbed from the alveoli must be replaced by fresh inspired gas mixture. This contains 80 per cent of nitrous oxide -80 per cent of 97 per cent of $1000 \mathrm{mls}=776 \mathrm{mls}$.

Thus an additional $776 \mathrm{mls}$ nitrous oxide are delivered to the alveoli per minute. 
When 40 per cent of nitrous oxide is administered, only $500 \mathrm{mls}$ are absorbed from the alveoli per minute. The contribution of nitrogen remains the same $(30 \mathrm{mls}$ per minute) and this now represents some 6 per cent of the absorbed nitrous oxide.

The fresh gas replacement, therefore contains: 40 per cent of 94 per cent of $500 \mathrm{mls}$ of nitrous oxide $=188 \mathrm{mls}$ nitrous oxide per minute.

In the first case 78 per cent of $\mathrm{N}_{2} \mathrm{O}$ taken from alveoli is automatically replaced by fresh $\mathrm{N}_{2} \mathrm{O}$ and in the second case only 38 per cent is so replaced. ${ }^{5}$

Thus, the rate at which the alveolar concentration of nitrous oxide approaches its inspired concentration increases with the inspired concentration itself. This is the concentration effect and really explains whatever virtue there is in breathing 100 per cent oxygen prior to administering nitrous oxide for induction of anaesthesia, since this can now be given in greater than usually acceptable concentrations (e.g. 100 per cent) for brief periods without producing hypoxaemia and thus, by permitting high inspired concentrations of the gas, one is able to produce high partial pressures of nitrous oxide in the alveolus and arterial blood with maximum speed. In addition, an extra volume of 100 per cent nitrous oxide is inspired because of the high net gas uptake. It is readily appreciated however that this is a very temporary dispensation only and a hazardous undertaking at the best of times. The virtue does not lie in "denitrogenation" and thus (as it were) providing greater "space" available for nitrous oxide.

The other virtues of breathing 100 per cent oxygen for several minutes before the induction of anaesthesia are, of course, quite a different question and must relate to the general hazards of hypoxia during induction and endotracheal intubation which may be slightly lessened by having a high partial pressure of oxygen in arterial blood at this time.

\section{Concentrating and second gas effects}

It is important to distinguish between the concentration effect and the concentrating effect. The concentration effect has just been described. The concentrating effect is the result of a rapid uptake of nitrous oxide from the alveolus during the first few minutes following the introduction of the agent. This rapid absorption has the effect of concentrating any other gases contained in the alveolus.

The second gas effect is not so much the result of increased alveolar ventilation produced by the rapid net uptake of nitrous oxide when it is first introduced as, in fact, by the concentrating effect produced by its uptake; indeed, the increased alveolar ventilation can only serve to reduce this effect, Figure 1. This demonstrates the concept of Stoelting and Eger of the sequence of events occurring after the introduction of nitrous oxide to a halothane and oxygen anaesthetic. ${ }^{15}$

The initial event following the rapid uptake of nitrous oxide is an apparent decrease in lung volume with a marked concentration of the second gas (halothane) from 1 per cent to 1.7 per cent (Figure 1 ).

The net gas uptake is replaced by fresh gas in the concentrations obtaining in the inspired mixture and this has the effect of reducing somewhat the concentration of the second gas (halothane). In this instance the concentration is reduced from 1.7 per cent to 1.4 per cent.

Under equilibrium conditions when inspired and alveolar concentrations of 


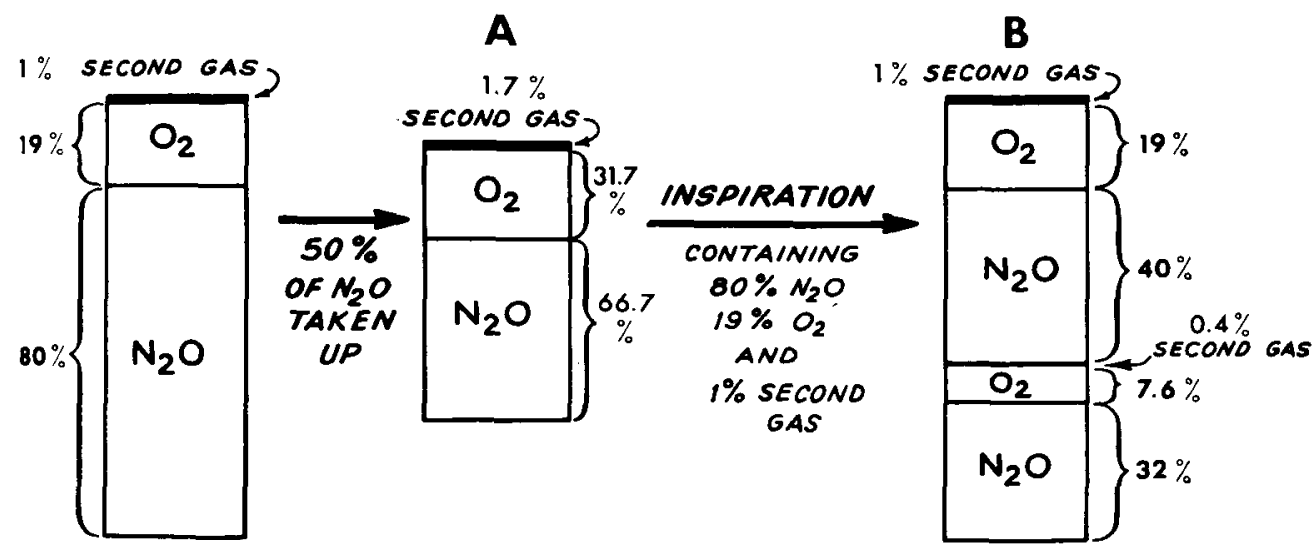

FIGURE 1. Second gas "concentrating" effect of nitrous oxide. It can be seen that the additional alveolar ventilation occasioned by the uptake of nitrous oxide actually dilutes the concentrated second gas such that from an initial concentration of 1 per cent to 1.7 per cent the final concentration is 1.4 per cent. (Stoelting and Eger. By permission of the authors and publishers.)

second gas are equal and when, therefore, an increase in alveolar ventilation might be anticipated to have but little effect upon the alveolar concentration, a second gas effect still persists (Figure 2) and this is actually diminished rather than increased by the increased alveolar ventilation secondary to the rapid uptake of nitrous oxide. Note that the least soluble agent (ethylene) shows the greatest concentrating effect.

\section{Cardiovascular effects of nitrous oxide}

It is worth giving some thought to the pharmacology of nitrous oxide with particular reference to the cardiovascular system. This aspect of the effect of nitrous oxide has had but little attention directed towards it by practising anaesthetists and careful observations from the field of clinical practice are wanting.

Recently, however, there has been a great deal of laboratory interest in the cardiovascular effects of nitrous oxide and it can no longer be held that these are always minimal or unimportant. There have been reports which indicate that in man, in the presence of halothane, the percentage of halothane in the inspired mixture might determine the effect observed when nitrous oxide is added to a halothane and oxygen anaesthetic. Cardiovascular system stimulation and subsequent depression have been reported at increasing inspired halothane concentrations. ${ }^{16}$

Ty Smith and his colleagues at Stanford have published some fascinating work on the effects of nitrous oxide in the presence of halothane anaesthesia. ${ }^{17}$ They show that there is, in general, a sympathomimetic effect. They demonstrated an increase in mean arterial pressure, right atrial pressure, systemic vascular resistance, and a rise in oesophageal temperature plus pupillary dilatation. It would be hard not to put a sympathomimetic connotation upon these results. It is interesting to note that when sympathetic and parasympathetic ganglionic blockade was produced by the administration of hexamethonium, the subsequent introduction of nitrous oxide produced a demonstrable increase in cardiac output. This was thought perhaps to 


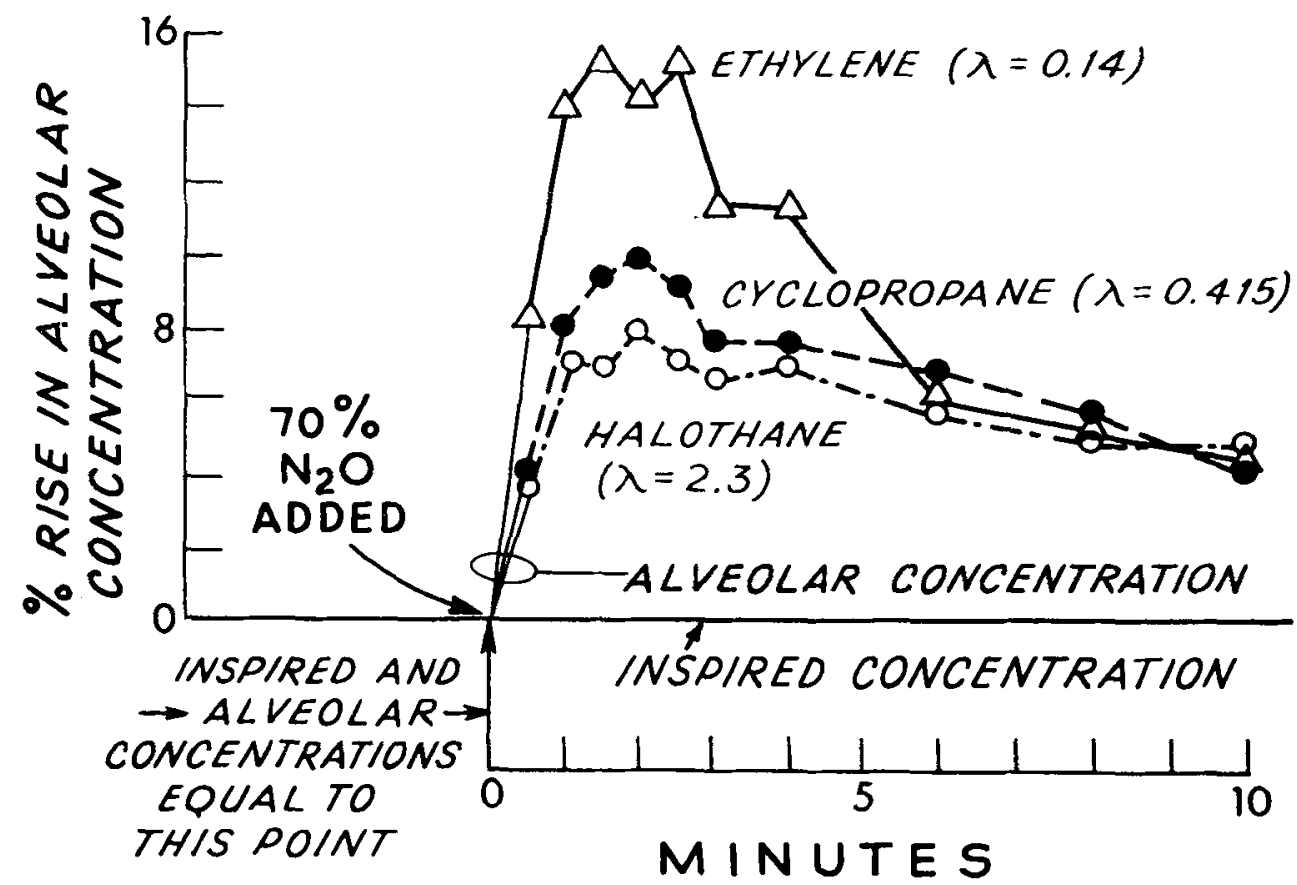

Figure 2. Second gas effect. Demonstrating the increased concentration of second gas (halothane, cyclopropane or ethylene) following the introduction of 70 per cent nitrous oxide after the production of equilibrium between inspired and alveolar concentrations. Increased alveolar ventilation due to rapid nitrous oxide uptake would be unlikely to produce this effect. (Stoelting and Eger. By permission of authors and publishers.)

represent a greater degree of parasympathetic than sympathetic ganglionic blockade produced by hexamethonium.

Smith and his colleagues have attributed the changes which they have demonstrated to an increased sympathetic discharge produced by nitrous oxide. The same authors have also reported a similar series of observations substituting diethyl ether for halothane. ${ }^{18}$ Here, once again, there appears to be some peripheral vasoconstriction without cardiac stimulation, following the administration of nitrous oxide in the presence of ether and oxygen anaesthesia. However, the other signs of increased sympathetic activity, such as pupillary dilatation and raised body temperature, observed in the presence of halothane, were absent in the case of diethyl ether.

Considering these two observations together, however, it appears reasonable to conclude that nitrous oxide has, in fact, the properties of an alpha adrenergic agonist.

Earlier investigations yielded different conclusions concerning the cardiovascular effects of this anaesthetic gas. Other workers, principally in Britain, showed what amounted to circulatory depression following the introduction of nitrous oxide to halothane anaesthesia. However, since blood levels and alveolar concentrations of halothane were not monitored this may perhaps have been a function of the second gas effect. ${ }^{19}$

The studies of Smith and his co-workers show a significant increase in plasma 
carpouc

OUTPUT

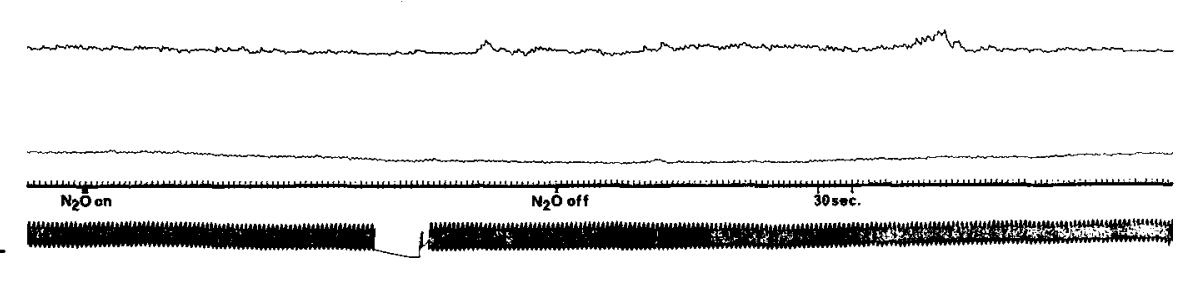

Frgure 3. Renal blood flow falling after the introduction of nitrous oxide. Discontinuing the gas permits the flow to return towards its previous level.

noradrenaline levels following the introduction of nitrous oxide to a halothane/ oxygen anaesthetic, thus lending credence to the impression that the gas is an indirect alpha adrenergic agonist. Adrenaline and noradrenaline are powerful constrictors of the glomerular afferent arterioles and an increase in these catecholamines in the circulation might be anticipated to produce some effect upon renal circulation. ${ }^{17}$

\section{Nitrous oxide and renal blood flow}

Some preliminary work which has been done in this centre concerning the effects of nitrous oxide on total renal blood flow may be of interest in this connection.

We measured renal blood flow, cardiac output and arterial blood pressure while maintaining body temperature between $37^{\circ} \mathrm{C}$ and $38^{\circ} \mathrm{C}$. Arterial blood gas tensions were maintained at $\mathrm{PO}_{2}$ more than $100 \mathrm{~mm} \mathrm{Hg}, \mathrm{PCO}_{2}$ between 30 and $38 \mathrm{~mm} \mathrm{Hg}$, and arterial blood $\mathrm{pH}$ between 7.35 and 7.46. Our experimental animals were mongrel dogs. The techniques employed to obtain these measurements have been described elsewhere. ${ }^{20}$

Anaesthesia was induced with thiopentone $20 \mathrm{mg} / \mathrm{Kg}$ and maintained with alphaprodine in $12 \mathrm{mg}$ increments. The animals were ventilated with 100 per cent oxygen. Skeletal muscle paralysis was produced by the administration of d-tubocurare in 6 to $9 \mathrm{mg}$ increments. We found that when nitrous oxide was introduced to this experimental preparation (66 per cent inspired nitrous oxide concentration) there was an early and sustained fall in renal blood flow, with no overall sustained fall in arterial pressure or cardiac output.

The decrease in renal blood flow which follows the introduction of nitrous oxide is shown in Figure 3. The decrease was reversed when nitrous oxide was removed from the inspired mixture.

In another series of experiments methoxyflurane and oxygen anaesthesia was maintained following thiopentone induction. Nitrous oxide (66 per cent) was introduced and at the same time methoxyflurane was discontinued. Once again we observed that the introduction of nitrous oxide was followed by a fall in renal blood flow and once again this occurred without any appreciable change in arterial pressure and cardiac output. Again, the reversal of these changes followed the removal of nitrous oxide (Figure 4). That this might represent a second gas effect appeared unlikely since methoxyflurane was removed from the inspired mixture, although some traces must persist as long as the gas is leached out from the conducting rubber conduits, in which it is very soluble. 


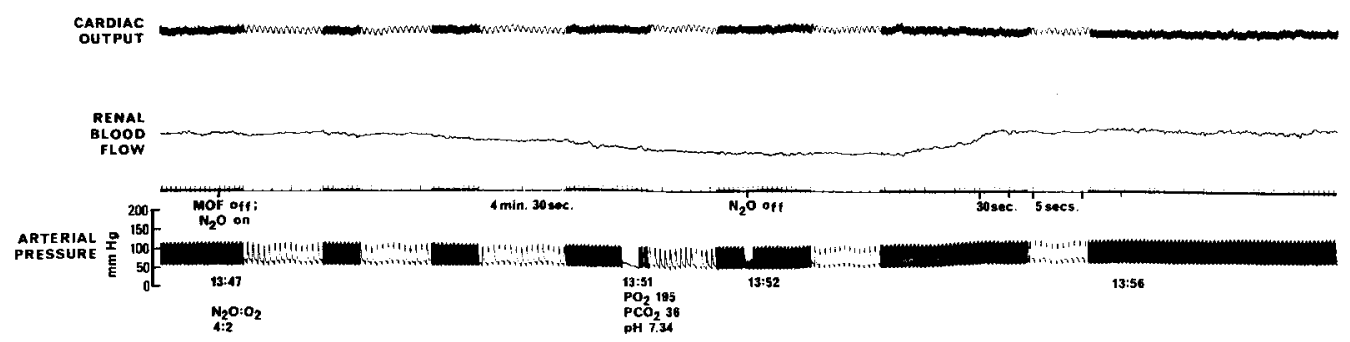

Figure 4. Nitrous oxide, in the presence of methoxyflurane, inducing a profound fall in renal blood flow. This fall is quickly reversed by discontinuing nitrous oxide.

The possible significance of this drop in renal blood flow following the administration of nitrous oxide is obvious and particularly in association with methoxyflurane - an agent already incriminated in the production of nephrotoxicity. ${ }^{21}$ Diminished renal vascular perfusion, in the presence of methoxyflurane might predispose to accumulation or persistence of fluoride ions resulting from the metabolic degradation of methoxyflurane and if, as seems likely, high output renal failure is due to free fluoride ion, especially in the vicinity of the collecting tubules, ${ }^{21}$ such diminished perfusion might contribute to the development of the syndrome by permitting longer contact between tubular cells and fluoride ions as a direct consequence of a fall in glomerular filtration rate.

The precise chain of events causing this fall in renal blood flow following the introduction of nitrous oxide remains to be investigated. It may be that other vascular beds in the splanchnic area or elsewhere are undergoing vasodilation. On the other hand, this may be an effect exercised upon renal glomerular afferent or efferent vessels by nitrous oxide, acting directly upon the smooth muscle of their walls or acting indirectly through the sympathetic nervous system. Further studies to investigate this phenomenon are proceeding.

The purpose of this brief review of some aspects of the clinical pharmacology of nitrous oxide has been to emphasize some of the known properties of the agent, and its potency both alone and in combination with other inhalational anaesthetics. Cardiovascular effects appear to be significant, although seldom given clinical consideration. The ability to depress renal blood flow which nitrous oxide appears to possess may perhaps be an important and undesirable action of the agent. This has not been the subject of much previous investigation.

\section{SUMMARY}

Nitrous oxide is commonly employed as an adjuvant in many forms of general anaesthesia and even as the sole inhalational anaesthetic agent. The history of its use is that of the specialty itself. Comparatively few studies had been performed to investigate the clinical pharmacology of nitrous oxide until recent years. The agent has a potency such that MAC is approximately 101. It is additive when employed with other general anaesthetic agents. The concentration effect determines the speed with which the inspired and alveolar concentrations approach one another. The concentrating effect is a function of the addition of nitrous oxide to an established general anaesthetic with some other agent and to a large extent explains the 
second gas effect. Nitrous oxide has marked cardiovascular effects (principally sympathomimetic) and also appears capable of reducing renal blood flow and thus inay predispose to the development of nephrotoxicity when employed in conjunction with methoxyflurane.

\section{RésuMé}

Le protoxide d'azote est régulièrement utilisé comme adjuvant dans plusieurs formes d'anesthésie générale et même comme seul agent anesthésique. Son usage remonte au début de la spécialité. Cependant ce n’est que récemment que des recherches cliniques et pharmacologiques furent effectuées concernant cet agent. Celui-ci a une puissance dont le MAC est environ 102. Il provoque une action additive lorsqu'il est utilisé avec d'autres agents anesthésiques généraux. L'effet de sa concentration détermine la vitesse avec laquelle les concentrations inspirées et alvéolaires s'approchent l'une de l'autre. L'effet de la concentration est en fonction de l'addition du protoxide d'azote au cours d'une anesthésie générale avec un autre agent et explique en grande partie l'effet du second gaz. Le protoxide d'azote a des effets (principalement sympathomimétiques) cardiovasculaires marqués et semble aussi capable de diminuer le débit sanguin rénal et ainsi peut favoriser le développement d'une néphrotoxicité lorsqu'on l'utilise avec le méthoxyllurane.

\section{REFERENCES}

1. KEys, T.E. The history of surgical anesthesia. Schuman's. New York (1945).

2. Lassen, H.C.A., Henricksen, E., Neukirch, F., \& Kristensen, H.S. Treatment of tetanus: severe bone marrow depression after prolonged nitrous oxide anesthesia. Lancet 1:527 (1956).

3. CARR, D.H. Anesthetic induced abortion: Editorial. Anesthesiology 35(4): 335 (1971).

4. Goodman, L. \& Gilman, A. The pharmacological basis of therapeutics. 4th edition. The Macmillan Corp. (1970).

5. SMiтh, W.D.A. Pharmacology of nitrous oxide - pharmacological topics in anesthesia. Ed. Millar, R.A. Int. Anes. Clin. (1971).

6. Eger, E. \& Saidman, L.J. Hazards of nitrous oxide anesthesia in bowel obstruction and pneumothorax. Anesthesiology 26: 61 (1965).

7. SAIDMAN, L.J. \& EGER, E. Change in cerebrospinal fluid pressure during pneumoencephalography under nitrous oxide anesthesia. Anesthesiology 26:67 (1965).

8. Hamilton, W.K. The limited clinical pharmacology of nitrous oxide. Clin. Pharm. and Therapeut. 4: 663 (1963).

9. Eger, E., Brandstater, B., Samman, L.J., Regan, M.J., Severinghaus, S.W., \& Munson, E.S. Equipotent alveolar concentrations of methoxyflurane, halothane, diethyl ether, Huroxene, cyclopropane, xenon and nitrous oxide in the dog. Anesthesiology 26: 771 (1965).

10. Eger, E., Saidman, L.J., \& Brandstater, B. Minimum alveolar anaesthetic concentration: a standard of anaesthetic potency. Anesthesiol. 26: 756 (1965).

11. Samman, L.J., Eger, E., Munson, E.S., Babad, A.A., \& Muallem, M. Minimum alveolar concentrations of methoxyflurane, halothane, ether and cyclopropane in man. Correlation with theories of anesthesia. Anesthesiology 28: 994 ( 1967 ).

12. Sampan, L.S. \& EGER, E. Effects of nitrous oxide and of narcotic premedication on the alveolar concentration of halothane required for anesthesia. Anesthesiology 25: 302 (1964).

13. Bendixen, H.H., Hedley-White, J., \& Laver, M.B. Impaired oxygen in surgical patients during general anaesthesia with controlled ventilation. New Eng. J. Med. 269: 991 (1963).

14. Campbell, E.J.M., Nunn, J.F., \& Peckett, B.W. A comparison of artificial and spontaneous respiration with particular reference to ventilation/blood flow relationships. Br. J. Anaesth. 30: 166 (1958). 
15. Stoelting, R.K. \& Eger, E. An additional explanation for the second gas effect: a concentrating effect. Anesthesiology 30: 273 (1969).

16. Horndein, T.F., Martin, W.E., Bonica, V., Freund, F.G., Paramentier, P. Nitrous oxide effects on the circulatory and ventilatory responses to halothane. Anesthesiology 31: 250 (1969).

17. Smith, N.T., Eger, E., Stoelting, R.K., Whayne, R.F., Cullen, D., \& Kadis, L.B. The cardiovascular and sympathomimetic response to the addition of nitrous oxide to halothane in man. Anesthesiology 32: 410 (1970).

18. SMrth, N.T., EgER, E.I., Culi'en, D.J. The cardiovascular responses to the addition of nitrous oxide to diethyl ether in man. Canad. Anaesth. Soc. J., 19: 142 (1972).

19. BLOCH, M. Systemic effects of nitrous oxide when used with halothane and oxygen anesthesia at normal body temperature. Brit. J. Anaes. 38: 119 (1966).

20. Leighton, Kenneth Macrae. Studies on the effects of succinylcholine upon the circulation of the anaesthetised dog. Canad. Anaesth. Soc. J. 18: 100 (1971).

21. Mazze, R., Trudele, J.R., \& Cousins, M.S. Methoxyflurane metabolism and renal dysfunction: clinical correlation in man. Anesthesiology 35: 247 ( 1971). 